\title{
Dietary sugar intake among preschool-aged children: a cross-sectional study
}

\author{
Anisha Mahajan MPH RD, Jessica Yu BSc, Jaimie L. Hogan BSc, Kira Jewell MSc RD, Alex Carriero BSc, \\ Angela Annis MSc, Adam Sadowski MMath, Gerarda Darlington PhD, Andrea C. Buchholz PhD RD, \\ Alison M. Duncan PhD RD, Jess Haines PhD RD, David W.L. Ma PhD; for the Guelph Family Health \\ Study
}

\section{Abstract}

Background: Excessive intake of sugar in young children is a public health concern. Our study objectives were to examine intakes of total, free and added sugar among preschool-aged children and to investigate their associations with body weight, body mass index Z-scores, percent fat mass and waist circumference.

Methods: The cross-sectional cohort study included preschool-aged children between 1.5 and 5 years of age, enrolled in pilot studies of the Guelph Family Health Study, Guelph, Ontario, from 2014 to 2016. Daily intake of total sugar was determined using a food processor software; daily intakes of free and added sugar, and food sources were determined through manual inspection of 3-day food records. Anthropometric measures were completed by trained research staff. We used linear regression models with generalized estimating equations to estimate associations between sugar intakes and anthropometric measures.

Results: We included 109 children (55 girls and 54 boys) in 77 families. Mean daily intakes were 86 (standard deviation [SD] 26) g for total sugar, 31 (SD 15) g for free sugar and 26 (SD 13) g for added sugar. Of participants, $80 \%(n=87)$ had intakes of free sugar greater than $5 \%$ of their daily energy intake. The most frequent food sources of free and added sugar were bakery products. A weak inverse association between free sugar intake (kcal/1000 kcal) and waist circumference $(\mathrm{cm})(\beta=-0.02,95 \%$ confidence interval -0.04 to -0.0009 ) was found, but no significant associations were noted between sugar intake and other anthropometric measures.

Interpretation: Most of the preschool-aged children in this study had free sugar intakes greater than current recommendations; overall, their total, free and added sugar intakes were not associated with the anthropometric measures. This study can be used to inform policy development for sugar intake in young children and apprise early intervention programs.

$\mathrm{D}$ ietary patterns begin in early childhood and can continue into adulthood. Thus, the early years are crucial for nutrition interventions and habit formation. ${ }^{1}$ Infants have a natural affinity to sweet foods overall, and preand postnatal exposures of added sugar are important. ${ }^{2,3}$ Genetic, environmental and cultural influences can increase preferences for sugary foods in children. ${ }^{2}$ However, there is a lack of high-quality research data on the dietary intake of sugars among young children, especially among infants and toddlers. ${ }^{4}$ Given that cardiometabolic risk markers may begin to emerge in children as young as 3 years of age, ${ }^{5}$ it is important to understand patterns of sugar intake and explore associations between intake of sugar and cardiometabolic risk markers (including anthropometric measures) in early life. This information can help inform policy development and programs for behaviour change intervention focused on early prevention.

Adverse effects of excessive sugar intake are a cause for global public health concern in all age groups. ${ }^{6}$ Overconsumption of sugar has been associated with increased risk of excessive weight gain, dental decay, poor diet quality and nutritional inadequacy in children and adolescents younger than 19 years. ${ }^{4,7,8}$ Excessive sugar intake has also been implicated in the development of

Competing interests: Alison Duncan is a member of the board of directors for the Canadian Nutrition Society, and David Ma is a former president of the Canadian Nutrition Society. David Ma and Jess Haines have received funding from Danone Institute North America and Danone Institute International. David Ma is a co-investigator of a study assessing nutrition knowledge among students that is funded by the Canadian Sugar Institute; he received no remuneration for his participation. No other competing interests were declared.

This article has been peer reviewed.

Correspondence to: David Ma, davidma@uoguelph.ca

CMAJ Open 2021 September 14. DOI:10.9778/cmajo.20200178 
high blood pressure and lipid abnormalities in children, ${ }^{4}$ which can lead to earlier presentation of chronic diseases in children than seen in previous generations. ${ }^{5}$

In most studies, sugar-sweetened beverages are the primary source of dietary sugar intake among children and adolescents. ${ }^{9}$ One study found that consumption of sugar-sweetened beverages in the first year of life was associated with a $13 \%$ increase in the risk of being overweight at 8 years of age. ${ }^{10}$ Recently, a study found that higher intakes of sugar-sweetened beverages and 100\% fruit juices were associated with increased risk of cardiometabolic risk factors in preschool-aged children. ${ }^{11}$ However, there are studies that have found no significant associations between intake of sugar-sweetened beverages and body weight or body mass index (BMI) Z-scores in preschool-aged and school-aged children. ${ }^{9}, 12$ Given these mixed findings and the primary focus on sugar-sweetened beverages, we embarked on our research study using detailed dietary assessments to examine sources of sugar intake broadly and investigate associations between dietary sugar intake and anthropometric measures in preschool-aged children.

There are multiple definitions in the research literature for added, free and total sugar. The World Health Organization (WHO) and Health Canada define added sugar as any type of dietary sugar that is added in processing or preparation of foods (e.g., sugars added when manufacturing sugarsweetened beverages and sweet treats such as lollipop, candies and fruit snacks). ${ }^{6,13}$ The term "free sugar" is a broader definition that includes added sugar and sugars that are naturally occurring in honey, syrups, fruit juices and fruit juice concentrates. ${ }^{6,13}$ Total sugars include free, added and natural sugars found in fruits, vegetables and unsweetened milk. ${ }^{13}$

Our study objectives were twofold. First, we sought to examine the daily intakes of total sugar, free sugar and added sugar, and the key food sources (by category) of free and added sugar among a sample of preschool-aged children. Our research study adopted the definitions from WHO and Health Canada for free and total sugar. However, the present study used a more common definition of added sugar used in the research literature, which includes sugars added during manufacturing, honey and syrups. ${ }^{14,15}$ Our second objective was to explore cross-sectional associations between intakes of total, free and added sugar, and anthropometric measures, including body weight, BMI Z-scores, body weight, waist circumference and percent body fat. We hypothesized that intake of free and added sugar in preschool-aged children would be positively associated with anthropometric measures.

\section{Methods}

\section{Study design}

This study is a cross-sectional secondary data analysis of a sample of preschool-aged children from the Guelph Family Health Study (GFHS). This research investigates the amount of total, free and added sugar intake, the associations with anthropometric measures and the key food sources of free and added sugar intake.

\section{Setting and participants}

The GFHS is a family-based lifestyle and obesity-prevention study, initiated in 2014 at the University of Guelph in Guelph, Ontario. The current cross-sectional cohort study includes data gathered from preschool-aged children from the GFHS pilot studies at baseline from 2014 to $2016 .{ }^{16}$ The purpose of the pilot studies was to test the feasibility and acceptability of our study methods.

Families with at least 1 child aged 1.5 to 5 years, who were not planning to move within the next year, were recruited from the Guelph-Wellington area through the Guelph Family Health Team, Guelph Community Health Centre and Ontario Early Years Centres. ${ }^{16}$ Our recruitment strategies were targeted and far-reaching, and included the use of study Facebook posts that were widely shared by community partners, and University of Guelph and GFHS websites. Posters and rack cards were displayed at the above community agencies and also at local recreation centres, libraries and other locations that provide services to young families. The participants completed an eligibility screener either online or over the phone with the study coordinator. ${ }^{16}$ Appendix 1, available at www.cmajopen.ca/content/9/3/ E855/suppl/DC1, provides more details on the ongoing GFHS. A gift card was provided to participants to acknowledge the time required.

\section{Study measures}

\section{Intake and sources of sugar}

Intakes of total, free and added sugar were assessed from the analysis of 3-day food records (2 weekdays and 1 weekend day). Parents were given paper food record forms, on which they recorded their child's (or children's) food and drink consumption, including amount and occasion of consumption, brand names of products and recipes for mixed foods. Food record data were entered into the ESHA Food Processor software for analysis of 3-day average nutrient intakes (version 11.6.441, 2015). Intake of total sugar was analyzed by the ESHA Food Processor; however, intakes of added and free sugar were determined through manual calculations and review of product and SmartLabel websites.

We adapted the algorithm of Louie and colleagues, ${ }^{14}$ which included a standardized, objective and stepwise approach to calculate content of added sugar (including honey and syrups) and free sugar (including foods with added sugar and $100 \%$ fruit juice and concentrates). ${ }^{14}$ This calculation has been used in other studies that investigated intake of free sugar among preschool-aged children. ${ }^{17,18}$ These calculations were performed by 2 data analysts to assure data quality. The data analysts followed a standard operating procedure to complete the calculation and worked closely together to ensure data consistency. There are limitations in the research literature, such as inconsistent definitions of free and added sugar ${ }^{2}$ and limited food composition databases that calculate amounts of added and free sugar. ${ }^{17}$ Intakes of total, free and added sugar were normalized to $\mathrm{kcal}$ per $1000 \mathrm{kcal} / \mathrm{d}$ for ease of comparison in the regression analysis. 
To identify sources of free and added sugar, we adapted the categorization system used by Bernstein and colleagues. ${ }^{19}$ About 17 broad categories of foods with free and added sugar were used to classify the sources consumed by our study population. ${ }^{19}$ The food records were reviewed to classify combined or stand-alone food items into food categories with free and added sugar. Our data analysts did not note any items with free sugar and added sugar in the food records for the vegetables or fish and seafood categories.

The following are examples of the items included in the prominent food categories seen in our study. Bakery products included items such as all breads and sweet breads, muffins, granola bars, pancakes and cookies. Beverages included both sweetened and unsweetened beverages such as juices and sweetened milk. Cereals and grain products included both hot and cold cereal options. Dairy products and substitutes included sweetened yogurts. Desserts included ice cream, frozen popsicles and Jell-O. Sugars and sweets included marshmallows, candies, syrups, fruit candies and sweetened jams.

\section{Anthropometric measures}

Anthropometric outcome variables included waist circumference, height, body weight, percent fat mass and BMI Z-scores. Repeated anthropometric measures were completed by trained research staff. Participants were instructed to remove any footwear and outer garments before measurements were taken. Waist circumference $(\mathrm{cm})$ was measured at the top of the iliac crest of participants' bare abdomen, using a non-elastic tape measure (Gulick II, Country Technology, Inc.). Height (cm) was measured using a child stadiometer. Height and waist circumference were measured in duplicate; if the values were within $0.5 \mathrm{~cm}$, then a mean value was calculated. Otherwise, a third measurement was taken and the mean of the 2 closest values was calculated. Body weight $(\mathrm{kg})$ was measured using an electronic weighing scale. BMI $\mathrm{Z}$-scores were calculated using the $\mathrm{R}$ package zscorer.

Percent fat mass was assessed using supine tetrapolar bioelectrical impedance analysis (BIA). Participants were instructed to avoid food or drink and vigorous physical activity for 30 minutes before the BIA assessment. Percent fat mass was calculated using Kushner and colleagues' total body water formula ${ }^{20}$ and Fomon and colleagues' hydration constants. ${ }^{21}$ Inter- and intrarater reliability of the BIA were previously determined in a sample of 6 children within the GFHS. ${ }^{22}$ The interrater coefficient of variation and reliability coefficient were 1.8 and 0.79 , respectively. ${ }^{22}$ Moreover, the intrarater coefficient of variation for the first observer was 0.05 and for the second observer was $0.15 .^{22}$ The intrarater reliability coefficients for the first observer was 0.05 and for the second observer was $0.15 .^{22}$

\section{Statistical analysis}

Data were analyzed using SAS University Edition version 9.4 (SAS Institute, Inc.). We used descriptive statistics to summarize children's sugar intake. Linear regression models using generalized estimating equations were fitted to estimate associations between sugar intake and anthropometric measures.
We used generalized estimating equations to account for any dependence between sibling participants ${ }^{23}$ and to attain $95 \%$ confidence intervals (CIs) for categories of sugar sources. The variables age and sex were identified as potential confounders and controlled for in the models that explored associations between sugar intake and children's body weight, fat mass and waist circumference.

\section{Ethics approval}

The study was approved by the University of Guelph Research Ethics Board (REB No. 14AP009).

\section{Results}

A total of 117 participants (83 families) were enrolled in the pilots. Participants were excluded from analyses if food records were incomplete $(n=4)$ or if breastfeeding replaced a meal, or exceeded 50 minutes or $625 \mathrm{~mL}$ of breastmilk per day $(n=4)$. Thus, our final analytic study sample included 109 preschool-aged children (55 girls and 54 boys) from 77 families.

Among our sample of 109 children, the mean age was 3.7 (SD 1.2) years, and $84 \%(n=92)$ of the participants were White. A total of $61 \%(n=47)$ of parents reported that their annual household income was greater than $\$ 80000$, and $41 \%$ $(n=32)$ had completed postgraduate training or degrees (Table 1). The following were the means noted for the anthropometric measures: body weight 16.2 (standard deviation [SD] 3.6) kg, BMI Z-score 0.6 (SD 1.0), waist circumference 50.8 (SD 4.6 ) cm and percent fat mass 29.8\% (SD 5.2\%).

\section{Sugar intake amounts and percent of total energy}

Mean daily intakes were 86 (SD 26) g (21.5 teaspoons) for total sugar, 31 (SD 15) g (7.8 teaspoons) for free sugar and 26 (SD 13) g (6.5 teaspoons) for added sugar (Figures 1 and 2). Of participants, $80 \%(n=87)$ had intakes of free sugar that exceeded $5 \%$ of their daily energy intake (Figure 1).

\section{Food sources of free and added sugar intakes}

We noted that $100 \%(n=109)$ of the children in our study sample were consuming free and added sugar from bakery products, $77 \%(n=84)$ from sugars and sweets, and $72 \%(n=$ 77) from cereals and grain products (Table 2). For free sugar intake, the top food sources were bakery products $(9.1,95 \%$ CI 8.0 to $10.2, \mathrm{~g})$, sugars and sweets $(7.5,95 \%$ CI 6.3 to $8.7, \mathrm{~g})$, and similar consumption of cereals and grain products $(4.2,95 \%$ CI 3.2 to $5.1, \mathrm{~g})$ and beverages $(10.5,95 \%$ CI 8.0 to $12.9, \mathrm{~g})$. For added sugar, the top food sources were bakery products $(9.1,95 \%$ CI 8.0 to $10.2, \mathrm{~g})$, sugars and sweets $(7.5$, $95 \%$ CI 6.3 to $8.6, \mathrm{~g})$, and cereals and grains $(4.2,95 \%$ CI 3.2 to $5.1, \mathrm{~g})$ (Table 3).

\section{Cross-sectional associations between sugar intakes and anthropometric measures}

Overall, children's total, free and added sugar intakes were not associated with the anthropometric measures explored (Table 4). Our study did find a significant but weak inverse 


\begin{tabular}{|c|c|}
\hline Characteristic & No. $(\%) \dagger$ \\
\hline \multicolumn{2}{|l|}{ Household income, Can\$ } \\
\hline Did not answer & $3(4)$ \\
\hline$<39000$ & $5(6)$ \\
\hline $40000-49999$ & $6(8)$ \\
\hline $50000-59999$ & $5(6)$ \\
\hline $60000-69999$ & $5(6)$ \\
\hline $70000-79999$ & $6(8)$ \\
\hline $80000-89999$ & $10(13)$ \\
\hline$>90000$ & $37(48)$ \\
\hline \multicolumn{2}{|l|}{ Parent education } \\
\hline Postgraduate training or degree & $32(42)$ \\
\hline University graduate & $30(39)$ \\
\hline College graduate & $7(9)$ \\
\hline $\begin{array}{l}\text { Some university, some college or } \\
\text { technical school }\end{array}$ & $8(10)$ \\
\hline \multicolumn{2}{|l|}{ Child ethnicity } \\
\hline White & $92(84)$ \\
\hline Other & $17(16)$ \\
\hline Child age, yr, mean \pm SD & $3.7 \pm 1.2$ \\
\hline \multicolumn{2}{|l|}{ Child sex } \\
\hline Male & $54(50)$ \\
\hline Female & $55(50)$ \\
\hline $\begin{array}{l}\text { Note: } \mathrm{SD}=\text { standard deviation. } \\
{ }^{*} \text { Children participants }(n=109) \text { and families } \\
\text { †Unless stated otherwise. }\end{array}$ & \\
\hline
\end{tabular}

association between free sugar intake and waist circumference (cm) $(\beta=-0.02,95 \%$ CI -0.04 to -0.0009$)$ (Table 4).

\section{Interpretation}

Our study investigated daily intakes of total, free and added sugar along with key food sources among preschool-aged children in the GFHS pilot studies. In addition, we examined cross-sectional associations between total, free and added sugar intakes and anthropometric measures. Our study found that young children are exceeding current national and global recommendations for dietary sugar intake. Young children are consuming free and added sugar from many food sources. Overall, there was no association between dietary sugar intake and anthropometric measures in our study participants.

Children's intake of total sugars $(86 \mathrm{~g} / \mathrm{d})$ in our sample was below the 2015 Canadian average of $101 \mathrm{~g} / \mathrm{d}$, or 24 teaspoons, for children aged 2 to 8 years. ${ }^{24}$ This age range may be too large for comparison, as intake of total sugars may change markedly between toddlers, preschoolers and children. The average added sugar intake of 6.5 teaspoons per day in our sample exceeds the recommendation of the American Heart Association (AHA) Scientific Statement, which recommends less than 6 teaspoons per day for children older than 2 years, and limiting or avoiding added sugar for children younger than 2 years. ${ }^{25}$ The World Health Organization recommends reducing free sugar intake to less than $10 \%$ of total energy intake but suggests further reducing this limit to below 5\%. ${ }^{6}$ Health Canada recommends the $10 \%$ limit. ${ }^{13}$ These recommendations are also endorsed by the Heart and Stroke Foundation of Canada. ${ }^{26}$ Furthermore, $20 \%$ of children had added sugar intake that exceeded the $10 \%$ limit as recommended by the AHA Scientific Statement ${ }^{25}$ and the 2015-2020 Dietary Guidelines for Americans (Appendix 1). ${ }^{27}$

The Institute of Medicine recommends a $25 \%$ upper limit of total energy intake for added sugars. ${ }^{28}$ Kranz and colleagues analyzed added sugar consumption among 2- to 5 -year-old American children through the Continuing Survey of Food Intake by Individuals. ${ }^{29}$ In this study, most participants consumed less than $25 \%$ of energy from added sugar, similar to our study sample. ${ }^{29}$ Among this US sample, the top food sources were fruit drinks, high-fat desserts and soft drinks, ${ }^{29}$ whereas in our sample bakery products were the top food source. Data from population-based surveys in Canada and the United States suggest that intake of sugarsweetened beverages has decreased over the past 10 years, which may explain the differences in top food sources of sugar intake in our study versus earlier studies with preschool-aged children. ${ }^{30,31}$

A total of $80 \%$ of preschool-aged children in our study had free sugar intakes that exceeded the $5 \%$ recommendation set by WHO, and $32 \%$ had intakes that exceeded the $10 \%$ recommendation. ${ }^{6}$ These results are similar to research by Devenish and colleagues, who analyzed free sugar intake among 2-year-old children in Australia. ${ }^{18}$ In this study, $71.1 \%$ of children exceeded the $5 \%$ of total energy recommendation, and $38 \%$ exceeded the less than $10 \%$ recommendation. ${ }^{18}$ The main sources of free sugar found in their sample were fruit juice, biscuits, cakes, desserts and confectionery, which were similar to the main sources of free sugar we found in our study. ${ }^{18}$

Examination of the cross-sectional associations between total, free and added sugar and anthropometric measures showed a small but significantly negative association between free sugar and waist circumference (Table 4). This result was normalized per $1000 \mathrm{kcal}$ for each participant and therefore may appear small and not clinically relevant. Considering a clinical scenario, the estimated mean difference in waist circumference for 2 children differing in free sugar intake by 2 SDs (100 kcal), assuming a $1000 \mathrm{kcal}$ diet, would be $-2 \mathrm{~cm}$ with a CI that goes as low as $-4 \mathrm{~cm}(-2.21,95 \% \mathrm{CI}-4.32$ to $-0.09, \mathrm{~cm})$. In this manner, a $2-\mathrm{cm}$ decrease in waist circumference is clinically interpretable; however, there is no research to date that suggests consuming more sugar results in a reduction in waist circumference. Interpreting these data within the context of other measures in this study, including nonsignificant associations for fat mass, BMI Z-scores and body weight, 


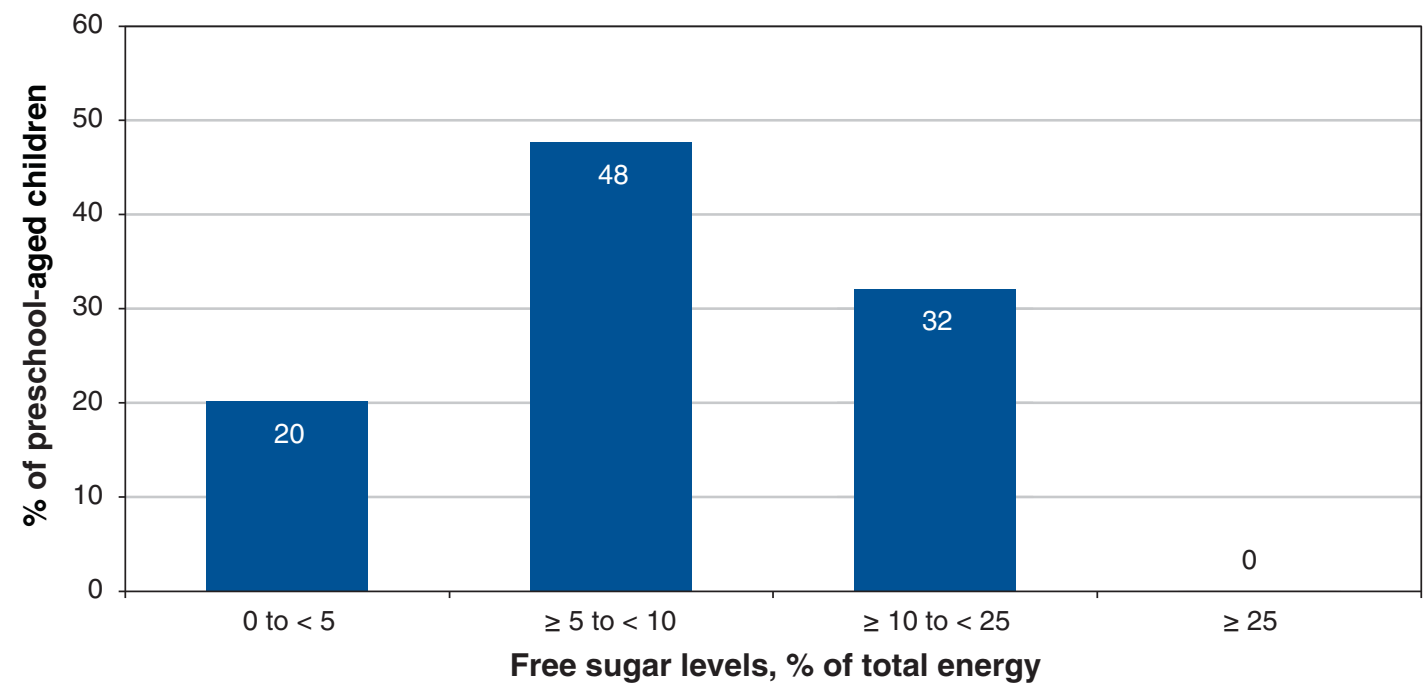

Figure 1: Percentages of preschool-aged children in the Guelph Family Health Study pilot studies $(n=109)$ consuming free sugars in the amounts of $0 \%$ to $<5 \%, \geq 5 \%$ to $<10 \%, \geq 10 \%$ to $<25 \%$, and $\geq 25 \%$ of total energy.

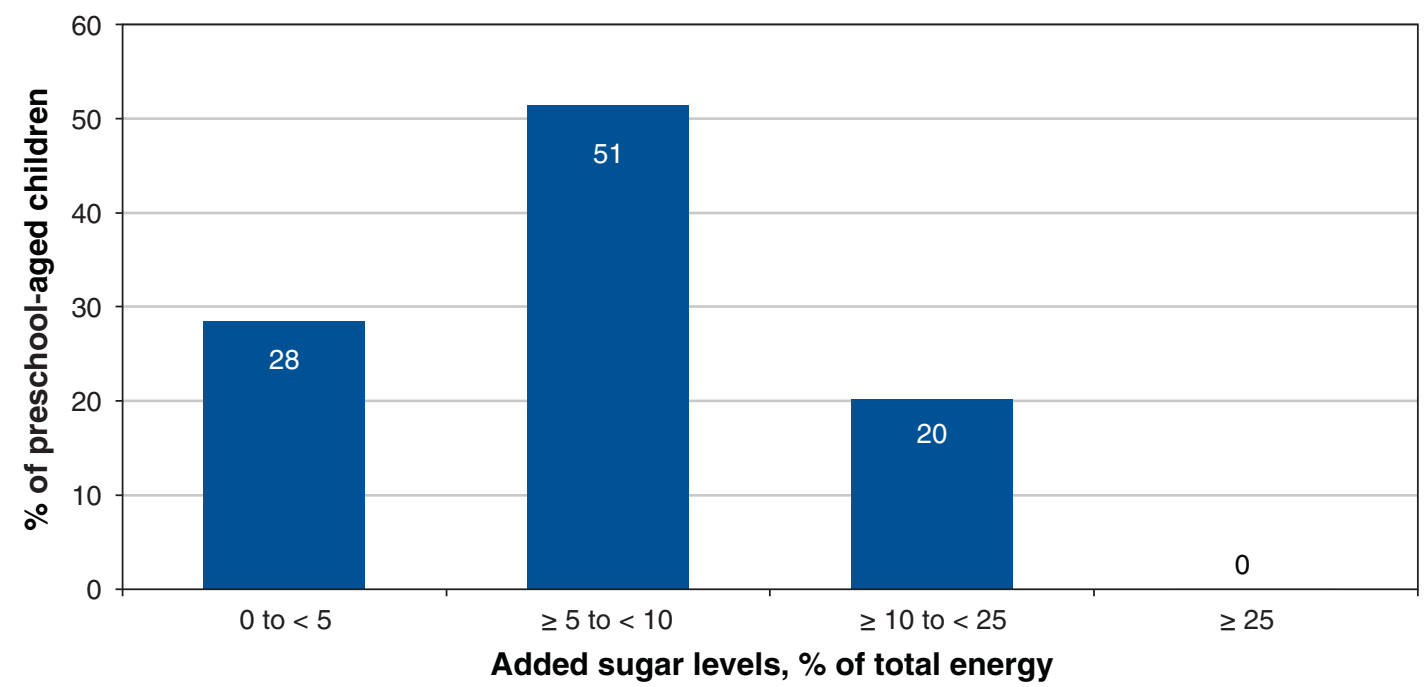

Figure 2: Percentages of preschool-aged children in the Guelph Family Health Study pilot studies $(n=109)$ consuming added sugars in the amounts of $0 \%$ to $<5 \%, \geq 5 \%$ to $<10 \%, \geq 10 \%$ to $<25 \%$, and $\geq 25 \%$ of total energy. Percentages do not sum to 100 because of rounding.

suggests that effects of free sugar on waist circumference are not likely plausible. Nevertheless, given the cross-sectional nature of these analyses, the data do not rule out potential long-term effects that require further follow-up.
Research studies linking sugar intake with weight gain and obesity in children are conflicting, as seen in systematic reviews. ${ }^{6}$ For instance, The Dortmund Nutritional and Anthropometric Longitudinally Designed (DONALD) Study 


\begin{tabular}{|c|c|c|c|}
\hline $\begin{array}{l}\text { Food source } \\
\text { category* }\end{array}$ & Type of sugar & $\begin{array}{l}\% \text { of free and } \\
\text { added sugar } \\
\text { intake } †\end{array}$ & $\begin{array}{l}\text { No. }(\%) \text { of children } \\
\text { consuming the } \\
\text { category } \ddagger\end{array}$ \\
\hline \multirow[t]{2}{*}{ Bakery products } & Free sugar & 29.6 & $109(100)$ \\
\hline & Added sugar & 34.9 & 109 (100) \\
\hline \multirow{2}{*}{$\begin{array}{l}\text { Sugars and } \\
\text { sweets }\end{array}$} & Free sugar & 18.8 & $84(77)$ \\
\hline & Added sugar & 22.1 & $84(77)$ \\
\hline \multirow{2}{*}{$\begin{array}{l}\text { Cereals and grain } \\
\text { products }\end{array}$} & Free sugar & 9.4 & $77(72)$ \\
\hline & Added sugar & 11.1 & $77(72)$ \\
\hline \multirow[t]{2}{*}{ Beverages } & Free sugar & 23 & $77(71)$ \\
\hline & Added sugar & 10.5 & $51(47)$ \\
\hline \multirow{2}{*}{$\begin{array}{l}\text { Dairy products } \\
\text { and substitutes }\end{array}$} & Free sugar & 6.4 & $63(58)$ \\
\hline & Added Sugar & 7.5 & $63(58)$ \\
\hline \multirow[t]{2}{*}{ Snacks } & Free sugar & 1.4 & $48(44)$ \\
\hline & Added sugar & 1.7 & $48(44)$ \\
\hline \multirow{2}{*}{$\begin{array}{l}\text { Sauces, dips and } \\
\text { condiments }\end{array}$} & Free sugar & 2.1 & $44(40)$ \\
\hline & Added sugar & 2.5 & $44(40)$ \\
\hline \multirow[t]{2}{*}{ Desserts } & Free sugar & 4.1 & $29(27)$ \\
\hline & Added sugar & 4.7 & $28(26)$ \\
\hline \multirow{2}{*}{$\begin{array}{l}\text { Mixed dishes, } \\
\text { sides and entrees }\end{array}$} & Free sugar & 1.2 & $21(19)$ \\
\hline & Added sugar & 1.3 & $20(18)$ \\
\hline \multirow{2}{*}{$\begin{array}{l}\text { Meats, eggs and } \\
\text { substitutes }\end{array}$} & Free sugar & 0.3 & $17(16)$ \\
\hline & Added sugar & 0.3 & $17(16)$ \\
\hline \multirow[t]{2}{*}{ Fruits } & Free sugar & 1.5 & $12(11)$ \\
\hline & Added sugar & 1.7 & $12(11)$ \\
\hline \multirow{2}{*}{$\begin{array}{l}\text { Other foods and } \\
\text { beverages }\end{array}$} & Free sugar & 1.1 & $10(9)$ \\
\hline & Added sugar & 1.3 & $10(9)$ \\
\hline \multirow[t]{2}{*}{ Nuts and seeds } & Free sugar & 0.1 & $7(6)$ \\
\hline & Added sugar & 0.1 & $7(6)$ \\
\hline \multirow{2}{*}{$\begin{array}{l}\text { Fats, oils and } \\
\text { vinegars }\end{array}$} & Free sugar & 0.1 & $5(5)$ \\
\hline & Added sugar & 0.2 & $5(5)$ \\
\hline \multirow[t]{2}{*}{ Soups } & Free sugar & 0.3 & $5(5)$ \\
\hline & Added sugar & 0.3 & $5(5)$ \\
\hline \multirow[t]{2}{*}{ Vegetables } & Free sugar & 0 & $0(0)$ \\
\hline & Added sugar & 0 & $0(0)$ \\
\hline \multirow[t]{2}{*}{ Fish and seafood } & Free sugar & 0 & $0(0)$ \\
\hline & Added sugar & 0 & $0(0)$ \\
\hline \multicolumn{4}{|c|}{ 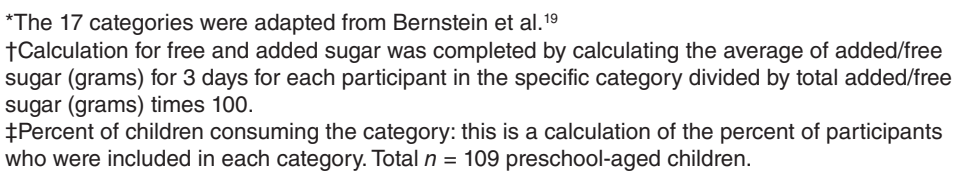 } \\
\hline
\end{tabular}

of 216 participants (age 0.5 to $7 \mathrm{yr}$ ) found that a high intake of added sugar in the first 2 years of life was associated with an increased BMI by the age of 7 years. ${ }^{3}$ By contrast, using data from the National Health and Nutrition Examination Surveys (1971-1975 and 1988-1994) from children aged 1 to 18 years, Song and colleagues found no association between total and 


\begin{tabular}{|c|c|c|c|c|}
\hline \multicolumn{5}{|c|}{$\begin{array}{l}\text { Table 3: Key food source categories* of contribution to free and added sugar } \\
\text { intake in preschool-aged children in the Guelph Family Health Study pilot studies }\end{array}$} \\
\hline $\begin{array}{l}\text { Food source } \\
\text { category }\end{array}$ & $\begin{array}{l}\text { Type of } \\
\text { sugar }\end{array}$ & $n$ & $\begin{array}{l}\text { Mean intake } \\
(95 \% \mathrm{Cl}), \mathrm{g}\end{array}$ & $\begin{array}{l}\text { Mean intake } \\
(95 \% \mathrm{Cl}), \mathrm{kcal}\end{array}$ \\
\hline \multirow{2}{*}{$\begin{array}{l}\text { Bakery } \\
\text { products }\end{array}$} & Free sugar & 109 & 9.1 (8.0 to 10.2 ) & 36.4 (36.0 to 40.8$)$ \\
\hline & Added sugar & 109 & 9.1 (8.0 to 10.2 ) & 36.4 (36.0 to 40.8$)$ \\
\hline \multirow{2}{*}{$\begin{array}{l}\text { Sugars and } \\
\text { sweets }\end{array}$} & Free sugar & 84 & 7.5 (6.3 to 8.7$)$ & 30.0 (25.2 to 34.8$)$ \\
\hline & Added sugar & 84 & 7.5 (6.3 to 8.6$)$ & $30.0(25.2$ to 34.4$)$ \\
\hline \multirow{2}{*}{$\begin{array}{l}\text { Cereals and } \\
\text { grain products }\end{array}$} & Free sugar & 77 & 4.2 (3.2 to 5.1$)$ & 16.8 (12.8 to 20.4$)$ \\
\hline & Added sugar & 77 & $4.2(3.2$ to 5.1$)$ & 16.8 (12.8 to 20.4$)$ \\
\hline \multirow[t]{2}{*}{ Beverages } & Free sugar & 77 & 10.5 (8.0 to 12.9$)$ & 42.0 (32 to 51.6$)$ \\
\hline & Added sugar & 51 & 6.5 (4.7 to 8.3 ) & 26.0 (18.8 to 33.2$)$ \\
\hline \multirow{2}{*}{$\begin{array}{l}\text { Dairy products } \\
\text { and substitutes }\end{array}$} & Free sugar & 63 & 3.4 (2.8 to 4.0$)$ & 13.6 (11.2 to 16.0$)$ \\
\hline & Added sugar & 63 & 3.4 (2.8 to 4.0$)$ & 13.6 (11.2 to 16.0$)$ \\
\hline \multirow[t]{2}{*}{ Snacks } & Free sugar & 48 & $1.0(0.6$ to 1.4$)$ & 4.0 (2.4 to 5.6$)$ \\
\hline & Added sugar & 48 & $1.0(0.6$ to 1.4$)$ & 4.0 (2.4 to 5.6$)$ \\
\hline \multirow{2}{*}{$\begin{array}{l}\text { Sauces, dips } \\
\text { and condiments }\end{array}$} & Free sugar & 44 & $1.6(1.2$ to 1.9$)$ & 6.4 (4.8 to 7.6$)$ \\
\hline & Added sugar & 44 & 1.6 (1.2 to 1.9$)$ & 6.4 (4.8 to 7.6$)$ \\
\hline \multirow[t]{2}{*}{ Desserts } & Free sugar & 29 & 4.7 (3.6 to 5.9 ) & 18.8 (14.4 to 23.6$)$ \\
\hline & Added sugar & 28 & 4.8 (3.6 to 6.0$)$ & 19.2 (14.4 to 24$)$ \\
\hline te: $\mathrm{Cl}=$ confiden & erval. & & $s$ that were consu & least $25 \%$ of the \\
\hline
\end{tabular}

Table 4: Cross-sectional associations between added, free and total sugar intakes and anthropometric measures, including body weight, BMI Z-scores, waist circumference and percent fat mass $(n=109)$

\begin{tabular}{|c|c|c|c|c|}
\hline & Body weight $(\mathrm{kg}) \dagger$ & BMI Z-scores & Waist circumference $(\mathrm{cm}) \dagger$ & Fat mass $(\%) \dagger$ \\
\hline Type of sugar* & $\beta(95 \% \mathrm{Cl})$ & $\beta(95 \% \mathrm{Cl})$ & $\beta(95 \% \mathrm{Cl})$ & $\beta(95 \% \mathrm{Cl})$ \\
\hline Added sugar & $-0.01(-0.03$ to 0.007$)$ & $-0.005(-0.01$ to 0.002$)$ & $-0.02(-0.05$ to 0.008$)$ & $-0.001(-0.03$ to 0.03$)$ \\
\hline Free sugar & $-0.011(-0.02$ to 0.002$)$ & $-0.004(-0.008$ to 0.0006$)$ & $-0.02(-0.04$ to -0.0009$)$ & $-0.003(-0.03$ to 0.02$)$ \\
\hline Total sugar & $-0.004(-0.01$ to 0.006$)$ & $-0.001(-0.005$ to 0.002$)$ & $-0.009(-0.02$ to 0.007$)$ & $0.0009(-0.02$ to 0.02$)$ \\
\hline
\end{tabular}

added sugar and BMI. ${ }^{32}$ This study suggested that total energy intake, rather than a specific nutrient, had a greater impact on children's BMI. ${ }^{32}$

There is a paucity of literature on sugar intake and anthropometric measures in preschool-aged children. Although overall, the research examining dietary sugar intake has been mixed in children, evidence shows intake of sugar-sweetened beverages is associated with cardiometabolic risk factors that include increased waist circumference and BMI Z-scores in preschool-aged children. ${ }^{33,34}$ This is likely due to the increased energy density in the overall dietary pattern with intake of sugar-sweetened beverages. Our findings indicated a significant negative association between free sugar intake and waist circumference (which is not clinically relevant owing to the small regression coefficient estimate) and do not suggest any other associations of sugar intake with anthropometric measures.

\section{Limitations}

Some limitations should be considered when interpreting our results. Our study sample consisted of $84 \%$ White participants, and more than $61 \%$ of participants had an annual household income greater than $\$ 80000$. Thus, our results may not be generalizable to children from diverse ethnic or low socioeconomic populations. A sample size calculation was not needed for the study, as the data were from pilot studies designed to address feasibility and all the available data were analyzed. Owing to the small sample, there is a risk of type 2 
error (false negatives), and thus, there is a need for replication in larger cohorts. Parent-reported food records were used to collect dietary data, which may lead to underreporting of children's sugar intake data owing to social desirability bias or errors in the reporting of children's intake.

In Canada, it is not required that companies identify the proportion of added and naturally occurring sugars on nutrition labels. This meant that for some products, such as infant formula, we were unable to differentiate the free and added sugars in the product. Our definition of added sugar was adapted from Louie and colleagues ${ }^{14}$ and includes honey and syrups. Although this definition is aligned with other research in this field, ${ }^{13,14}$ it has been debated ${ }^{35,36}$ as it is not consistent with current WHO and Health Canada definitions. ${ }^{6,13}$

\section{Conclusion}

Our study found that young children are exceeding current Canadian and WHO recommendations for dietary sugar intake. Preschool-aged children are consuming free and added sugar from many food sources. Overall, there was no association with dietary sugar intake and anthropometric measures in our study participants. The study findings support current recommendations that preschool-aged children should limit free and added sugar intake to establish healthy dietary patterns early in life. Although our study does not provide evidence linking sugar intakes and anthropometric measures, most children exceeded the WHO recommendations for free sugar intake.

This study can inform health care professionals and policymakers about the current consumption patterns of sugars in young children, as there is currently limited research available for this age group. Our data regarding key food and beverage sources of sugar intake among preschool-aged children can be used to guide dietary and policy advice for preschoolaged children. Given the limited research examining sugar intake among young children and the impact on cardiometabolic risk factors in early years, further investigation of dietary sugar intake (amount and sources) and longitudinal associations with anthropometric measures are warranted in preschool-aged children.

\section{References}

1. Mikkilä V, Räsänen L, Raitakari OT. Consistent dietary patterns identified from childhood to adulthood: the cardiovascular risk in Young Finns Study. Br f Nutr 2005;93:923-31.

2. Fidler Mis N, Braeger C, Bronsky J, et al.; ESPGHAN Committee on Nutrition. Sugar in infants, children and adolescents: a position paper of the European Society for Paediatric Gastroenterology, Hepatology and Nutrition Committee on Nutrition. 7 Pediatr Gastroenterol Nutr 2017;65:681-96.

3. Herbst A, Diethelm K, Cheng G, et al. Direction of associations between added sugar intake in early childhood and body mass index at age 7 years may depend on intake levels. 7 Nutr 2011;141:1348-54.

4. Herrick KA, Fryar CD, Hamner HC, et al. Added sugars intake among US infants and toddlers. F Acad Nutr Diet 2020;120:23-32.

5. Skinner AC, Perrin EM, Moss LA, et al. Cardiometabolic risks and severity of obesity in children and young adults. N Engl F Med 2015;373:1307-17.

6. Guideline: sugars intake for adults and cbildren. Geneva: World Health Organization. 2015.

7. Keller A, Della Torre SB. Sugar-sweetened beverages and obesity among children and adolescents: a review of systematic literature reviews. Child Obes 2015;11:338-46.
8. Elfassy T, Adjoian T, Lent M. Sugary drink consumption among NYC children, youth, and adults: disparities persist over time, 2007-2015. 7 Community Health 2019;44:297-306.

9. Davis JN, Lee S. Chapter 17: Dietary sugars, obesity and chronic diseases in children. In: Dietary Sugars and Health. Boca Raton (FL): CRC Press; 2014:245-55.

10. Blum JW, Jacobsen DJ, Donnelly JE. Beverage consumption patterns in elementary school aged children across a two-year period. 7 Am Coll Nutr 2005; 24:93-8.

11. Eny KM, Jeyakumar N, Dai DWH, et al. Sugar-containing beverage consumption and cardiometabolic risk in preschool children. Prev Med Rep 2020; 17:101054.

12. Newby PK, Peterson KE, Berkey CS, et al. Beverage consumption is not associated with changes in weight and body mass index among low-income preschool-aged children in North Dakota. 7 Am Diet Assoc 2004;104:1086-94.

13. Canada's dietary guidelines for bealth professionals and policy makers. Ottawa: Health Canada; 2019.

14. Louie JCY, Moshtaghian H, Boylan S, et al. A systematic methodology to estimate added sugar content of foods. Eur 7 Clin Nutr 2015;69:154-61.

15. Bailey RL, Fulgoni VL, Cowan AE, et al. Sources of added sugars in young children, adolescents, and adults with low and high intakes of added sugars. Nutrients 2018;10:102.

16. Haines J, Douglas S, Mirotta JA, et al.; Guelph Family Health Study. Guelph Family Health Study: pilot study of a home-based obesity prevention intervention. Can 7 Public Health 2018;109:549-60.

17. Crowe M, O'Sullivan M, Casetti O, et al. Estimation and consumption pattern of free sugar intake in 3-year-old Irish preschool children. Eur 7 Nutr 2020;59:2065-74.

18. Devenish G, Golley R, Mukhtar A, et al. Free sugars intake, sources and determinants of high consumption among Australian 2-years-olds in the SMILE Cohort. Nutrients 2019;11:161.

19. Bernstein JT, Shermel A, Mills CM, et al. Total and free sugar content of Canadian prepackaged foods and beverages. Nutrients 2016;8:582.

20. Kushner RF, Schoeller DA, Field CR, et al. Is the impendence index (ht $\left.{ }^{2} / \mathrm{R}\right)$ significant in predicting total body water? Am 7 Clin Nutr 1992;56:835-9.

21. Fomon SJ, Haschke F, Ziegler EE, et al. Body composition of reference children from birth to age 10 years. Am 7 Clin Nutr 1982;35(Suppl):1169-75.

22. Jewell K. Examining the association between household chaos and child diet quality. Masters of Science thesis. Guelph (ON): University of Guelph; 2019.

23. Liang KY, Zeger SL. Longitudinal data analysis using generalized linear models. Biometrika 1986;73:13-22.

24. Langlois K, Garriguet D, Gonzalez A, et al. Changes in total sugars consumption among Canadian children and adults. Health Rep 2019;30:10-9.

25. Vos MB, Kaar JL, Welsh JA, et al.; American Heart Association Nutrition Committee of the Council on Lifestyle and Cardiometabolic Health; Council on Clinical Cardiology; Council on Cardiovascular Disease in the Young; Council on Cardiovascular and Stroke Nursing; Council on Epidemiology and Prevention; Council on Functional Genomics and Translational Biology; Council on Hypertension. Added sugars and cardiovascular risk in children: a scientific statement from the American Heart Association. Circulation 2017; $135: e 1017-34$.

26. Sugar, heart disease and stroke [position statement]. Ottawa: Heart and Stroke Foundation; 2014.

27. 2015-2020 dietary guidelines for Americans. 8th ed. Washington (DC): U.S. Department of Health and Human Services and U.S. Department of Agriculture; 2015.

28. Institute of Medicine. Summary tables, dietary reference intakes. In: Dietary reference intakes for energy, carbohydrate, fiber, fat, fatty acids, cholesterol, protein, and amino acids. Washington (DC): The National Academies Press; 2005: $1319-31$.

29. Kranz S, Smicklas-Wright H, Siega-Riz AM, et al. Adverse effect of high added sugar consumption on dietary intake in American preschoolers. 7 Pediatr 2005;146:105-11.

30. Jones AC, Kirkpatrick S, Hammond D. Beverage consumption and energy intake among Canadians analysis of 2004 and 2015 national dietary intake. Nutr 7 2019;18:60.

31. Marriott BP, Hunt KJ, Malek AM, et al. Trends in intake of energy and total sugar from sugar sweetened beverages among children and adults, NHANES 2003-2016. Nutrients 2019;11:2004.

32. Song WO, Wang Y, Chung CE, et al. Is obesity development associated with dietary sugar intake in the US? Nutrition 2012;28:1137-41.

33. Kosova EC, Auinger P, Bremmer AA. The relationships between sugarsweetened beverage intake and cardiometabolic markers in young children. 7 Acad Nutr Diet 2013;113:219-27.

34. Seferidi P, Millett C, Laverty AA. Sweetened beverage intake in association to energy and sugar consumption and cardiometabolic markers in children. Pediatr Obes 2018;13:195-203.

35. Khan TA, Sievenpieper JL. Controversies about sugars: results from systematic reviews and meta-analyses on obesity, cardiometabolic disease and diabetes. Eur 7 Nutr 2016;55(Suppl 2):25-43.

36. Mela DJ, Woolner EM. Perspective: Total, added or free? What kind of sugars should we be talking about? Adv Nutr 2018;9:63-9. 
Affiliations: Departments of Human Health and Nutritional Sciences (Mahajan, Yu, Hogan, Carriero, Duncan, Ma), and Family Relations and Applied Nutrition (Jewell, Buchholz, Haines), and Guelph Family Health Study (Annis, Sadowski), and Department of Mathematics and Statistics (Darlington), University of Guelph, Guelph, Ont.

Contributors: Anisha Mahajan conducted and interpreted the data analysis and wrote the manuscript. David Ma and Jess Haines are codirectors of the Guelph Family Health Study (GFHS) and supervised this project. Gerarda Darlington was the statistical advisor. Andrea Buchholz supervised body composition measurements for the study, and Alison Duncan supervised the dietary data collection and analysis. Both were co-advisors for this project. These authors critically evaluated the results of this project. Angela Annis assisted with data acquisition, and Jessica Yu, Jaimie Hogan, Kira Jewell, Alex Carriero and Adam Sadowski assisted with data cleaning and data review. All authors reviewed and revised the manuscript, gave final approval of the version to be published and agreed to be accountable for all aspects of the work.

Funding: This research was funded by the Heart and Stroke Foundation of Canada, the Canadian Institutes of Health Research and the Health for Life Initiative at the University of Guelph. None of the organizations had any role in the project design, data collection, analyses, interpretation of data or writing of the manuscript.

Content licence: This is an Open Access article distributed in accordance with the terms of the Creative Commons Attribution (CC BY-NC-ND 4.0) licence, which permits use, distribution and reproduction in any medium, provided that the original publication is properly cited, the use is noncommercial (i.e., research or educational use), and no modifications or adaptations are made. See: https://creativecommons.org/licenses/by-nc-nd/4.0/

Data sharing: The GFHS welcomes external collaborators. Interested investigators can contact GFHS investigators to explore this option, which preserves participant confidentiality and meets the requirements of our research ethics board, to protect human subjects. Owing to research ethics board restrictions, we do not make participant data publicly available.

Acknowledgements: The authors acknowledge Wellington-DufferinGuelph Public Health and the Guelph Family Health Team for their collaborative support of this work.

Supplemental information: For reviewer comments and the original submission of this manuscript, please see www.cmajopen.ca/content/9/3/ E855/suppl/DC1. 